\title{
Resolving Conflict Through Explicit Bargaining
}

\author{
Elizabeth Heger Boyle \\ Stanford University
}

Edward J. Lawler

University of Iowa

Social Forces (1991), 69(4), 1183-1204

This article is based in part on the first author's MA. thesis, conducted under the supervision of the second author. The project was partially supported by a grantfrom the National Science Foundation to the second, author, and both authors would like to thank Rebecca Ford, Edgar Kiser, Barry Markovsky, Charles W. Mueller, and Cecilia Ridgeway for helpful comments. Direct correspondence to Edward J. Lawler, Department of Sociology, University of Iowa, Iowa City, IA 52242. 


\begin{abstract}
This article analyzes the impact of conciliatory initiatives on conflict resolution in twoparty bargaining. It specifically develops and tests a theory of unilateral initiatives derived from Osgood's (1962) notion of Graduated and Reciprocated Initiatives in Tension Reduction (GRIT). The major propositions of the theory indicate that, given a pattern of mutual resistance or hostility, unilateral initiatives and tit-for-tat retaliation in response to punitive action will produce more conciliation and less hostility by an opponent. To test the theory, a bargaining setting was created in a laboratory experiment in which parties exchanged offers and counteroffers on an issue across a number of rounds while also having the option to engage in punitive action against one another. The results indicated that (1) unilateral initiatives produced more concession making and less hostility than a reciprocity strategy, and (2) tit-for-tat retaliation heightened hostility initially but reduced it over time. The article suggests some general, abstract conditions under which two parties in conflict can produce conciliation and reach agreements without the intervention of third parties.
\end{abstract}


This article addresses the following question: Given a social structure that produces conflict behavior, how can one party break a pattern of conflict and generate mutual conciliation? We assume a structure that pits two groups against one another and an effort by each group to deal with the conflict via explicit bargaining, i.e., through an explicit exchange of offers and counteroffers. Entering explicit bargaining involves a decision by parties to consider, if not actively seek, a compromise solution to the conflict (Bacharach \& Lawler 1980; Chertkoff \& Esser 1976; Schelling 1960). Examples include contract negotiations between labor and management, SALT negotiations of the Soviet Union and United States, plea bargaining in the criminal justice system, as well as the development of a divorce settlement by lawyers representing each side. ${ }^{1}$

The onset of explicit bargaining does not necessarily cease mutually damaging action (e.g., wars, strikes, protests) or even lead to much compromise. The bargaining setting often becomes simply another context within which the conflict is enacted and within which actors seek to gain advantage rather than produce mutual conciliation. As a result, it is not unusual for bargaining to fail outright or to produce conflict resolution only after lengthy periods of impasse from which parties suffer high costs. There are at least two general obstacles to conciliation that make conflict resolution problematic, even after parties reach the bargaining table.

First, social conflict typically has a social-structural foundation. Each bargainer (or the group each represents) occupies a structural position in a larger system, a position with interests that diverge from those associated with the structural position of the opponent. Parties to bargaining interpret, translate, or otherwise make concrete the interests embedded in their structural positions (see Lawler n.d.) and, in the process, they may exacerbate the structurally based conflict. Parties have an incentive to manage impressions carefully, and their interests 
shape the perceptions upon which they each make tactical decisions. When their interests have a structural foundation, the stakes are higher and the differences between parties' interpretations of the situation and between their preferences are particularly difficult to bridge.

A second, related obstacle is that even if both parties adopt a goal of mutual conciliation, there is no assurance that they can convince each other of this fact. Consequently, conflict may continue unabated despite such compatible goals. To resolve conflict, some degree of trust is necessary, according to much social psychological evidence (Pruitt 1981); yet trust is difficult to develop, because early periods of explicit bargaining often contain patterns of mutual resistance or hostility that reflect posturing, suspicion, and ultimately the structural position of the parties. Thus, when the conflict has a structural foundation and posturing occurs early in the bargaining, reaching an agreement expeditiously or without the intervention of third parties (e.g., allies, mediators, arbitrators) becomes highly problematic.

The primary purpose of this article is to examine the success of a particular bargaining tactic — unilateral initiatives — at overcoming the obstacles to conciliation noted above. Our focus is informed by a tactical approach to the bargaining process, which emphasizes the moves and countermoves of parties, conceptualizes such moves as tactics of influence, and analyzes tactics as efforts to manipulate an opponent (see Bacharach \& Lawler 1981; Lawler \& Bacharach 1987; Lawler, Ford \& Blegen 1988). In brief, a tactic is a move or set of moves that can be directed at a variety of specific objectives, e.g., testing the opponent's resolve, gaining information about the opponent, issuing a warning, fostering a particular definition of an issue, presenting a particular image or identity, punishing the opponent. However, most tactics fall into two general classes (Pruitt 1981): hostile and conciliatory. Unilateral initiatives, in our theory, 
are a form of conciliatory tactic suggested by Osgood's (1962) analysis of Graduated and Reciprocated Initiatives in Tension Reduction (GRIT).

Osgood (1962) originally proposed GRIT as a conceptual framework for ending the arms race between the United States and the Soviet Union. The fundamental premise is as follows: If graduated, reciprocal negative action produced the arms buildup, then graduated, reciprocal positive action is the pathway to reducing it. The gears of the escalator need only be shifted to reverse. The primary tactic for shifting the gears involves a series of unilateral initiatives. Examples of initiatives are Anwar Sadat's trip to Israel in 1978 and John F. Kennedy's unilateral cessation of above-ground nuclear testing in 1962 (see Etzioni 1967). However, the ideas underlying GRIT need not be limited to international conflicts or to the particular ones of concern to Osgood. From the conceptual and empirical literature in this tradition, one can extrapolate a set of parsimonious theoretical principles indicating when parties might resolve conflict themselves, without reliance on mediators and arbitrators. These principles — composing a theory of unilateral initiatives — are explicated and tested experimentally in the following pages.

\section{Background of the Theory}

From early social psychological work on matrix games through the recent simulation work of Axelrod (1984), the standard answer to the question of how parties can produce conciliation by an opponent has been reciprocity (e.g., Deutsch et al. 1967; Oskamp 1971; Wrightsman, O'Conner \& Baker 1972; Komorita \& Esser 1975). Most of the research has been conducted in iterative prisoner's dilemma games in which reciprocity is defined as a matching 
(i.e., tit- for-tat) strategy whereby an actor makes the same choice (cooperative vs. competitive) as the opponent did on the immediately preceding trial. Experimental research demonstrates that a matching strategy generally produces more cooperation than most (if not all) other viable strategies (e.g., Oskamp 1971; Wrightsman, O'Conner \& Baker 1972), and computer simulations by Axelrod (1984) have shown that this strategy is the best among a very large set of possibilities identified by bargaining scholars. In sum, reciprocity seems to be a simple and straightforward solution to the strategic dilemma faced by a party wishing to produce mutual conciliation.

However, there are several unresolved theoretical issues in the literature on reciprocity (see Deutsch 1973; Deutsch et al. 1967; Gouldner 1960; Youngs 1986). One is an issue addressed by Osgood (1962), i.e., how to develop reciprocal positive action if a pattern of mutual resistance or hostility already has been established. Tit-for-tat reciprocity tends to create and maintain a "lock-in" of competition or hostility once defection occurs (Axelrod 1984), and, consistent with the implications of Osgood (1962), Patchen (1987) argues that unilateral initiatives represent the most effective tactic for breaking a lock-in of mutual competition.

Conciliatory actions that are unilateral pose a difficult impression management problem for a party considering such a tactic. This problem is reflected in several studies of explicit bargaining, which indicate that large concessions or concession patterns that create an image of softness actually reduce the concession making of an opponent (Benton, Kelley \& Liebling 1972; Komorita \& Brenner 1968; Yukl 1974). The classic explanation for such findings is that an image of softness raises the opponent's aspiration level, which, in turn, reduces the opponent's inclination to yield (Siegel \& Fouraker 1960). From this perspective, unilateral initiatives may convey weakness and produce exploitation rather than conciliation by the opponent. The tangible and intangible costs of unilateral initiatives that fail can be substantial. 
To deal with the potential of exploitation, Osgood (1962) stresses that the initiatives should be small and symbolic but substantial enough to foster an atmosphere of trust. Taking the practical purposes of the GRIT notion to heart, Lindskold (1978) proposes ten specific guidelines for making unilateral initiatives effective: (1) express a sincere desire to reduce tension; (2) publicly announce each conciliatory initiative; (3) carry out each initiative on schedule; (4) invite, but do not demand, reciprocation; (5) continue conciliatory initiatives even without reciprocation; (6) make the initiative unambiguous and susceptible to verification; (7) retain your retaliatory capability; (8) respond tit for tat to exploitation; (9) match reciprocal concessions by the other; and (10) diversify the initiatives. Action in accord with these guidelines ostensibly will restore some of the trust lost in a pattern of mutual hostility or impasse.

Several studies support the notion that conciliatory initiatives of one sort or another elicit more cooperation in prisoner's dilemma or bilateral monopoly games than do strict matching or reciprocity strategies (e.g., Hamner 1974; Lawler \& MacMurray 1980; Lindskold 1979; Lindskold \& Aronoff 1980; Lindskold \& Collins 1978; Lindskold \& Finch 1981; Patchen 1988). However, assuming a buildup of hostility as an initial condition, some guidelines seem more important than others, and it is not clear what basic theoretical principles are at work here. Separation of the most fundamental ones from those less fundamental will facilitate the development of some simple and parsimonious theoretical principles.

In this article, we develop two central, or core, themes of the conceptual and research literature on GRIT: the role of unilateral initiatives (e.g., guidelines 2-6 and 9-10) and tit-for-tat retaliation (e.g., guidelines 7 and 8 ). We assume that the ultimate goal of conflict resolution is contingent on parties' achievement of two intermediate goals: (1) an increase in the opponent's concessions (which the party can then reciprocate), and (2) a decrease in the opponent's use of 
punitive tactics. From this perspective, unilateral initiatives and retaliation tactics are the central independent variables, and concession and punitive behavior are distinct dependent variables. The next section specifies the fundamental theoretical connections among these independent and dependent variables.

\section{A Theory of Unilateral Initiatives}

One problem with the original formulation of Osgood (1962) and related work is a lack of clarity on what sort of context or situation is at issue. The scope conditions of Osgood's (1962) incipient theory are unspecified, resulting, for example, in ambiguity about whether the GRIT notion is intended to apply equally to efforts at reaching the bargaining table and to efforts at concluding an agreement once the bargaining table has been reached. In conjunction with a lack of explicitness about the main predictions, insufficient specification of the intended scope conditions has contributed to substantial variation in how the theory of unilateral initiatives has been interpreted, applied, and tested (e.g., Hamner 1974; Lindskold \& Finch 1981; Patchen 1988; Pilisuk 1984;). As a first step, we offer herein a simple theoretical formulation with delimited scope conditions, using the existing literature on GRIT heuristically rather than literally. The scope conditions and core propositions are discussed, in turn, below. 


\section{SCOPE CONDITIONS}

The theoretical formulation is designed to apply to conflict situations that encompass the following five conditions.

\section{Two Parties Are Engaged in Explicit Bargaining}

The parties have consented to bargain, and so unilateral initiatives are not designed to produce bargaining but to bring it to a successful conclusion, presumably without the direct aid or interference of third parties (e.g., allies, mediators, arbitrators). Given the properties of explicit bargaining defined earlier (e.g., mutual acknowledgement of the bargaining, an issue with a range of possible solutions, an exchange of offers and counteroffers), a prisoner's dilemma does not adequately capture the context and thus is not an appropriate laboratory setting for testing this formulation. This is an important point, because nearly all research on the GRIT notion has been conducted in iterative prisoner's dilemma games. ${ }^{2}$

Similar to most social psychological work on explicit bargaining, the theory of unilateral initiatives assumes that parties begin bargaining with an individualistic orientation, i.e., attempting to maximize their own gain without regard to that of others. Because explicit bargaining is mixed-motive, however, there is likely to be some oscillation by actors on the meaning of maximization — specifically, on whether it suggests more concretely a goal of gaining an advantage over the opponent or a goal of mutual conciliation. 
Each Party Lacks (and Believes the Other Lacks) Knowledge of the Other's Payoff Across Possible Solution Points

This assumption is adopted in most social psychological research on bargaining, and it reflects an effort to incorporate or take into account some ambiguity typical of real-world bargaining. Incomplete information on payoffs accentuates the importance of the impressionmanagement aspect of concession behavior.

Each Party Has a Coercive Capability (i.e., the Ability to Damage Outcomes Already Possessed by the Opponent) and, Therefore, the Option of Using Damage Tactics

In conjunction with the first scope condition, this means that positive (concession) and negative (punitive) actions are analytically and empirically separable, a condition seemingly critical to Osgood's (1962) original formulation but frequently neglected in subsequent research using the prisoner's dilemma. ${ }^{3}$ For initial purposes, the theory of unilateral initiatives assumes that parties have equal coercive power capabilities and that they have knowledge of each other's coercive capabilities. 
The Setting Is a Bilateral Monopoly, Meaning That Parties Cannot "Leave the Field"

In this context, parties are committed to bargaining interaction for a fixed period, which, theoretically, is part of the "consent to bargain." Parties do not necessarily have to yield or make concessions, but their communication of proposals or offers must continue for a fixed period of time.

A Pattern of Mutual Resistance and Hostility Is Established in the Early Phase of Explicit Bargaining

This condition broadens the only clear scope condition — an impasse — in Osgood's (1962) original discussion and is consistent with most research on GRIT (see Hamner 1974; Lindskold 1978). In explicit bargaining, a pattern or history of mutual resistance should foster mutual impressions of firmness, which prevent a unilateral initiative (all other things being equal) from being perceived as a sign of weakness and thereby avert exploitation (see relevant reviews in Chertkoff \& Esser 1976; Rubin \& Brown 1975; Pruitt 1981). The initial pattern of mutual hostility in the context of a consent to bargain essentially establishes conditions making unilateral initiatives potentially effective, though parties may have difficulty recognizing this potential.

While the scope conditions suggest a more limited theory of unilateral initiatives than implied by Osgood (1962) and Lindskold (1978), the above context corresponds with important features of many interpersonal, labor- management, interorganizational, and international negotiation situations where parties have taken an initial step toward conflict resolution by 
initiating explicit bargaining. Our theoretical strategy is to begin with these more limited, or narrow, set of conditions.

\section{CORE PROPOSITIONS}

The core propositions of the formulation are diagrammed in Figure 1. Unilateral initiatives refer to a series of small concessions undertaken independent of the opponent's response. The retaliation tactic refers to a tit-for-tat response (by the user of unilateral initiatives) to punitive action by the opponent. Trust is a hypothetical construct defined as a dispositional attribution forming the basis for an expectation of cooperation. ${ }^{4}$ Concessions refer to the magnitude of yielding by the opponent; punitive tactics refer to the frequency of damaging action by the opponent; and agreement, of course, refers to whether or not the bargainers actually reach a solution to the issue at hand.

The fundamental claims, based on Figure 1 and given the scope conditions, are as follows:

Proposition 1: If party A engages in a series of unilateral initiatives, party B's concession making will increase and its use of punitive tactics will decrease.

Proposition 2: If party A adopts a retaliation tactic in response to punitive action, party B's concession making will increase and its use of punitive tactics will decrease.

For unilateral initiatives (proposition 1), a single intervening mechanism — attributions of trust — is the primary explanation found in the GRIT literature (Osgood 1962; Lindskold 
1978). Initiatives, which are unilateral and lack an explicit expectation of reciprocity, ostensibly foster an image of sincerity, reliability, and reasonableness, which in turn produces larger concessions and fewer punitive tactics by the opponent. A dispositional attribution of trustworthiness enhances the confidence of the target that concessions will be reciprocated. In the case of retaliation (proposition 2), a tit-for-tat response to punitive action makes such action costly to the opponent and also helps to ensure that unilateral initiatives do not communicate excessive softness or vulnerability. A complex interplay of intervening mechanisms, involving both the experience of cost and the creation of an image of firmness, should operate in the case of the retaliation tactic. Trust is included in the theoretical model at this point because of its prominence in the related literature (see Blalock 1989; Lindskold 1978; Pruitt 1981) and because of Axelrod's (1984) suggestion that trust is not necessary to account for the development of tacit bargains in an iterative prisoner's dilemma.

Insert Figure 1 Here

The two propositions above will be tested in a laboratory context, using a simulated actor (A) in order to instantiate the specified behavior. To test the first proposition, a unilateral initiatives condition will be compared with a reciprocity (no-initiatives) control condition; and to test the second proposition, a pattern of retaliation will be compared with a no-retaliation condition. 


\section{Methods}

\section{EXPERIMENTAL DESIGN}

A bargaining relationship between a subject and a programmed other was created in a laboratory setting. The setting was a modified bilateral monopoly similar to that used in some recent work on coercive capability in conflict (see Lawler \& Bacharach 1987; Lawler, Ford \& Blegen 1988). A $2 \times 2$, completely randomized factorial design manipulated the unilateral initiatives (present vs. control) and retaliation behavior (present vs. control) of the programmed other. Eighty subjects (all male) were assigned randomly to one of the four cells (twenty per cell). ${ }^{5}$

\section{PROCEDURES}

Subjects were scheduled in groups of two to four. When they arrived at the laboratory, the experimenter led them to a cubicle in one of several rooms. Each cubicle was equipped with a computer terminal on which the subjects would read instructions for the study, and the experimenter informed them that they would be bargaining with a participant in another room.

The instructions gave a detailed explanation of the setting and bargaining procedures. To give the conflict a minimal intergroup character, subjects were placed in the role of representing a constituency. Specifically, subjects represented a group, called Beta, negotiating with a group, called Alpha. The bargaining issue was an abstract set of agreement levels (numbered 11-49), each with profit (points) attached to it. The issue could represent the price of a product in a 
buyer-seller situation, a wage increase in a labor-management context, or a trade agreement between nations (for similar procedures, see Bacharach \& Lawler 1981; Lawler \& Bacharach 1987; Lawler, Ford \& Blegen 1988).

A profit list showed subjects the number of points they would win at each agreement level. The maximum number of points that each bargainer could receive from the bargaining was 300, and subjects received more points the closer the agreement was to level 11 . The instructions did not provide any concrete information on Alpha's profit, except to note that Alpha preferred higher agreement levels. Instructions indicated further that there had been preliminary negotiations in which Alpha had offered 49 and Beta had offered 11. This served to justify the ends of the issue continuum. The instructions indicated that subjects should attempt to maximize their own points regardless of the other's profit.

Bargainers had a second source of profit beyond the issue under negotiation, specifically, an account worth 300 points. This account was equal in value to the outcomes at stake in the bargaining and symbolized the current, existing resources under the control of or already possessed by a bargainer. Such resources were not under direct negotiation, but each bargainer could use damage tactics (i.e., fines) to reduce the opponent's account. This coercive power capability was high and equal across experimental conditions, i.e., each had the capacity to reduce the other's account to zero through the repetitive use of fines.

The maximum number of bargaining rounds was twenty. Each round consisted of the following sequence: (1) an offer by Alpha (the programmed other), (2) an offer by Beta (the subject), (3) a standardized message from Alpha, and (4) a choice among standardized message options by the subject. Offers and messages were entered on the computer terminal and transmitted back and forth by the computer. When making an offer, subjects could repeat their 
last offer, accept the last offer of the programmed other, or make a concession. Subjects could not retract concessions or move backward to a previous position on die issue continuum.

Turning to the punitive options, subjects could send a "fine," a "warning," or "no message." A fine was a damage tactic that reduced the other's account by 30 points, and each side was allowed a maximum of 10 fines (damage tactics). A warning was a threat to use a fine in the future, and there was no limit on the number of warnings. The no-message option was designed to ensure subjects understood that a fine or warning was not necessary and also to keep the sequence of steps in each round constant. Throughout the bargaining, the computer terminal displayed all the offers and messages of each bargainer.

Agreements could occur in one of two ways: the subject could at any time produce conflict resolution by agreeing to the last offer of the programmed other, or the subject could concede to the point that the program called for an offer equal to or lower than the preceding offer of the subject (recall that the subject preferred lower offers on the issue continuum). In both cases, the subject's offer produced the agreement.

The bargaining ceased if there was no agreement after twenty rounds. At this point, the computer relayed point winnings to subjects, summing the points from the bargaining (which was zero if there was no agreement) and those remaining in the account. Following completion of the questionnaire, subjects were debriefed about the fictitious other and paid a set amount greater than their point winnings would have indicated. 


\section{ESTABLISHING A PATTERN OF MUTUAL RESISTANCE}

To implement a key scope condition of the theory of unilateral initiatives, the first five rounds contained a standard, uniform sequence of resistance and hostility by the programmed other. The specific action of the programmed other was as follows: (1) offers of 49 on each of the first five rounds, i.e., no concessions, and (2) damage tactics (fines) on the first and fifth round and a threat tactic (warning) on the third and fourth rounds. Based on previous work (Lawler \& MacMurray 1980) and extensive pretesting, we expected the subject's response to indicate a pattern of mutual resistance or hostility by the end of the fifth round.

The project considered the scope condition to be met if during the first five rounds the subject (1) repeated an offer (i.e., made no concession) three consecutive times, (2) used damage tactics (fines) twice and conceded three or fewer units on the issue continuum, or (3) used more damage tactics than the programmed other. Eleven subjects failed to meet these conditions and were excluded.

\section{EXPERIMENTAL MANIPULATIONS}

Unilateral initiatives and retaliation behavior by the programmed other created the experimental manipulations. The programmed other either initiated a series of unilateral concessions or did not initiate concessions and either retaliated in response to the subject's fines or did not retaliate. The manipulations were in force from the sixth to the tenth round of the bargaining. 
In the initiatives condition, the programmed other (after sticking at 49 for the first five rounds) initiated concessions during rounds 6-10 as follows: 48,47,45, 42, and 39, respectively. In the no-initiative (reciprocity) control condition, the programmed other did not initiate any concessions but fully reciprocated any concessions made by the subject during this period. After the tenth round (and across experimental conditions), the programmed other reciprocated the magnitude of each concession in the offer immediately following the subjects. Reciprocation after the series of unilateral initiatives is the pattern most consistent with the original GRIT formulation.

In the retaliation condition, whenever the subject used a damage tactic (fine), the programmed other used a damage tactic on the next round. In the no-retaliation control condition, damage tactics by the subject were not reciprocated and so were not used at all by the programmed other after the first five rounds. The retaliation-versus-control manipulation was in force from round 6 to the conclusion of the bargaining. Across conditions, warnings by the programmed other did not occur from round 6 on.

\section{DEPENDENT VARIABLES}

The primary dependent variables suggested by the theory of unilateral initiatives are damage tactics (fines) and concession levels (magnitude). The analysis distinguishes the early response to the experimental manipulations (during rounds 6-10) from the later, or subsequent, response (rounds 11-20). Thus, the number of fines sent by subjects in the early phase (rounds 610) and the number sent in the later phase (rounds 11-20) are analyzed, as is the magnitude of the subject's concession during these phases of the bargaining (i.e., offer 10 minus offer 6 and the 
last offer minus offer 10). Conflict resolution refers to whether or not an agreement was reached by the end of the twentieth bargaining round.

Other analyses examine information from a postexperiment questionnaire, administered by the computer program at the end of the bargaining. This questionnaire included three items that measured the subject's perceptions of how the programmed other changed over the session, i.e., to what extent the other became more or less trustworthy, more or less reasonable, and more or less inclined to use damage tactics. Ttoo other items asked about the predictability of the programmed other's behavior as the session progressed, i.e., to what extent the programmed other's concession behavior became more or less predictable and to what extent the message behavior became more or less predictable. Each of the five questions contained the same sevenpoint response format, with labels defining the points on the continuum. Other items with the same format served as a check on the manipulations.

\section{Results}

The success of the manipulations was indicated by postexperiment questionnaire items asking subjects, "To what extent did the other bargainer initiate offers?" and "To what extent did the other bargainer reciprocate your fines?" Consistent with our intent, subjects perceived more initiation in the initiatives condition than in the reciprocity control condition $[F(1,79) *$

$24.52, p<.001]$ and more reciprocation of fine messages in the retaliation condition than in the noretaliation control condition $[F(1,79)=67.36, p<.001]$. 
Insert Table 1 Here

CONCESSION MAGNITUDE

The mean magnitude of concessions by experimented conditions can be found in Table 1 (rows 1 and 2).

Early Phase (Rounds 6-10)

Consistent with the theory of unilateral initiatives, an analysis of variance for the early phase showed that the immediate response to unilateral initiatives was to concede significantly more $\left[2.425, F(1,79)=25.24, p<.0001, M^{\prime} s=5.88\right.$ vs. 2.42$]$ than in the reciprocity control condition. The retaliation tactic did not affect concession making $[F(1,79)=2.12, p<.15$, $M^{\prime} s=3.65$ (no retaliation) vs. 4.65 (retaliation)], and the interaction of initiatives and retaliation was not significant $[F(1,79)=1.19$, n.s. $]$. Thus, the results for the early response to unilateral initiatives support the theory, and those for retaliation do not.

Later Phase (Rounds 11-20)

Across early and later phases, the effect of unilateral initiatives on total concession is significant and in the right direction $[F(1,79)=5.62, p<.025]$. However, the analysis for concession magnitude during the subsequent or later phase does not reveal significant effects $\left(F^{\prime} s<l\right)$. One feasible reason for this result is that as explicit bargaining proceeds toward some 
fixed deadline (in this case, twenty rounds), the pressures to concede are contingent in part on how much an actor has yielded earlier. Larger concessions earlier in the bargaining can result in smaller concessions later in the bargaining and vice versa, assuming a fixed maximum of yielding. These are often termed "end effects," and they occur in both real world and laboratory contexts. A by-blocks (i.e., repeated-measures) analysis of variance was conducted to pursue this issue.

By-Block Analysis

For this analysis, the last fifteen rounds of bargaining were divided into three blocks of five rounds each. To deal with cases where the bargaining ended with agreement in less than twenty rounds, the average concession per round was calculated for each block, and only cases that went at least eighteen rounds were included in the analysis. This criterion resulted in the loss of eight cases distributed fairly evenly across conditions.

Insert Figure 2 Here

The resulting $2 \times 2 \times 3$ analysis, with block as a repeated measure, revealed one effect involving the block variable - an interaction of unilateral initiatives and block $[F(2,136)=$ $6.89, p<.001]$. The pattern of the interaction (see Figure 2) is compatible with the end effects interpretation. Unilateral initiatives continued to have a positive effect on concessions during the first five rounds (block 2) after the initiatives phase was completed, and subjects in the reciprocity-only (i.e., no-initiatives) condition, having yielded little during the first two blocks, 
appear to have attempted to catch up as the deadline approached. The most critical point is that the predicted positive impact of unilateral initiatives continued beyond the time when the initiatives were in force. Further corroboration of this point is yielded by a regression analysis, which will be reported later.

\section{DAMAGE TACTICS (FINES)}

Early Phase (Rounds 6-10)

Analysis of the mean frequency of fines (see Table 1, row 3) during the early phase revealed two significant findings: (1) unilateral initiatives produced fewer damage tactics by subjects than the reciprocity (no-initiatives) control $\left[F(1,79)=10.31, p<.01, M^{\prime} s=.80 \mathrm{vs}\right.$. 1.75], and (2) the immediate impact of the retaliation tactic was to increase the use of damage tactics by subjects $\left[F(1,79)=15.11, p<.001, M^{\prime} s=1.850\right.$ vs. .700]. The results for unilateral initiatives are consistent with the theory under discussion, whereas those for retaliation are contrary to it. 
Later Phase (Rounds 11-20)

The only significant finding for the frequency of damage tactics in the later phase is a main effect for unilateral initiatives. Fewer damage tactics were used when the programmed other had previously undertaken a series of unilateral concession initiatives $[F(1,79)=$ 13.36, $p<.001, M^{\prime} s=1.50$ vs. 3.03]. Thus, combining the results for early and later phases, there is strong support for the negative effect of unilateral initiatives on punitive action, when compared to a reciprocity-only control condition. ${ }^{6}$

The effects of retaliation on the use of damage tactics are obviously more complex than the impact of unilateral initiatives. The main effect for retaliation is not statistically significant for the later phase $\left[F(1,79)=1.58\right.$, n.s., $M^{\prime} s=2.00$ vs. 2.52$]$, and the pattern is actually the opposite of that observed for the early phase (see Table 1). A by-block analysis, identical in form to that for concession magnitude, was conducted to ferret out the apparent differences across time.

By-Block Analysis

The $2 \times 2 \times 3$ analysis of variance, with block as a repeated measure, revealed a significant retaliation by block interaction $[F(2,136)=7.13, p<.001]$. When the programmed other retaliated consistently, the use of damage tactics decreased over time, whereas a lack of retaliation resulted in an increase of such tactics. This finding is actually consistent with the theory of unilateral initiatives if parties need more than five rounds to fully discern the retaliation-versus-no- retaliation pattern in the programmed other's behavior. We conclude that 
over time the effect predicted by the theory tends to occur in the retaliation condition. It is also interesting that a party who adopts a policy of nonretaliation faces increasing hostility over time.

\section{CONFLICT RESOLUTION}

A log-linear analysis of the proportion of agreements for each experimental condition revealed a main effect for unilateral initiatives in the predicted direction $(x<9.58, p<.01)$ as well as an interaction effect $(x=4.84, p<.05)$. The highest rate (i.e., 75\%) of conflict resolution occurred when the programmed other combined unilateral initiatives with a policy of tit-for-tat retaliation. The rate of agreement was well below $50 \%$ in all other conditions (see Table 1). These findings support the interactive effects of retaliation and unilateral initiatives on conflict resolution suggested in some related literature (Patchen 1987).

\section{QUESTIONNAIRE DATA}

The five items noted earlier were factor analyzed using a varimax rotation with a limit of two factors. Conceptually, two items reflect the trust variable (i.e., the perceived trustworthiness and perceived reasonableness of the programmed other), and two reflect the perceived predictability of the programmed other's behavior. The fifth item, the perceived change in the other's inclination to fine, does not fit either the trust or predictability rubric. Consistent with such reasoning, the factor analysis revealed separate factors for trust and predictability (see Table 2). ${ }^{7}$ The Cronbach alpha for the trust index was .65, but for predictability it was only .22. 
An analysis of variance was conducted for the two-item index of trust (summing the raw scores). Consistent with the theory of unilateral initiatives, perceived trust was greater in the initiatives than in the reciprocity control $[F(1,79)=16.60, p<.001]$, and neither the retaliation main effect nor the initiatives- by-retaliation interaction was statistically significant $\left(F^{\prime} s<1\right)$. The perceived predictability of the programmed other's behavior does not have theoretical importance but could suggest whether we inadvertently created differing levels of predictability across experimental conditions. However, the results for the two-item index and each item separately (given the low reliability of the index) did not reveal significant effects and thereby indicate no such differences $\left(F^{\prime} s<1\right)$.

\section{REGRESSION ANALYSIS}

A regression analysis of concession and damage behavior in the later phase (rounds 1120) was designed to test the mediating effects of trust for unilateral initiatives. Such a test must be considered provisional, since trust was measured on the postexperiment questionnaire. However, since the questionnaire items were retrospective, a regression analysis is still informative.

Table 3 contains the standardized regression coefficients from three regression equations for concession magnitude and the frequency of damage tactics. The first equation includes only the two manipulated variables (plus the interaction); trust is added to the second equation; and the third equation controls for all previous concession and damage behavior (i.e., concession magnitude and the frequency of fines summed across all prior bargaining phases, including the first five rounds). 
Insert Table 2 Here

The regression results support several points. First, in accord with the theory of unilateral initiatives, higher levels of trust enhanced concession making by subjects $(\beta=.386, p<.01)$ while also reducing their use of damage tactics $(\beta=-.440, p<.001)$. Second, trust mediated the impact of unilateral initiatives on damage tactics. The mediation was virtually complete (equation 3) when concession and damage behavior in the first half of the experiment was controlled (indirect effect=.227). Third, some evidence of a suppressor effect supports our earlier suggestion of end effects. There was virtually no effect for initiatives ( $\beta=-.043)$ without trust and other controls in the equation (equation 4); however, with the inclusion of these controls (equation 6), the coefficient for the direct effect of initiatives increased considerably $(\beta=$ -.290), though it remained nonsignificant statistically $(p<.11)$. The most telling result is that the sign of the direct effect of initiatives on concession magnitude was negative, and the sign of the indirect effect through trust was positive.

Insert Table 3 Here

More specifically, the positive indirect effect reflects a large, positive impact of initiatives on trust $(\beta=.515, p<.001)$, which, when combined with the impact of trust on concessions ( $\beta=.386$ ), yields a positive indirect effect of reasonable size (.199). This indirect effect indicates that through trust, unilateral initiatives have the predicted effect on concession making. The trend toward a negative direct effect, on the other hand, is consistent with the fact 
that the immediate positive impact of initiatives during rounds 6-10 reduces the potential yielding that can occur later in the bargaining. These direct and indirect coefficients essentially distinguish the end effects from effects supportive of the theory. Overall, the regression analysis supports the mediating effect of trust and suggests that the predicted impact of unilateral initiatives on concession behavior is contingent on such mediation.

\section{Summary and Discussion}

The theoretical formulation presented above, developed inferentially from the GRIT notion (Osgood 1962), can be construed as an effort to understand when and how two actors might resolve conflict without the intervention of third parties, such as mediators and arbitrators. To the degree that actors "freely" and consensually develop their own agreement, they presumably will take more responsibility for it and have a stronger commitment to it over time (see Bacharach \& Lawler 1981: chap. 6). Third parties, of course, may be critical to conflict resolution in many contexts, but to the degree that such parties formally or informally "force" agreements, the commitment of conflicting actors to the agreements should be lower and the need for frequent renegotiation and vigorous monitoring greater. For such reasons, a theory of unilateral initiatives, specifying conditions under which parties can resolve their conflict themselves, could form a unique niche in sociological analyses of conflict resolution processes.

Conflict and its resolution is of long-standing interest to sociologists. Most sociological work adopts a structuralist approach that (1) traces the source of conflict to divergent interests of groups, collectivities, or classes; (2) examines the mobilization of those interests; and (3) implicitly attributes "solutions" of conflict to enduring power and status hierarchies that 
distinguish groups and individuals and that are imbued with legitimacy (e.g., Dahrendorf 1959; Simmel 1950). Though there are certainly exceptions, sociologists have directed much less attention to the processes through which conflicting actors - whether they be individuals, groups, organizations, or societies — reach mutually agreed- upon solutions (for a few exceptions, see Bacharach \& Lawler 1980, 1981; Blalock 1987, 1989; Kriesberg 1973; Lawler n.d.; Patchen 1988; Strauss 1978). Greater attention to the conflict or bargaining process does not necessarily require a focus on the interpersonal dynamics between negotiators (see Strauss 1978), but it does require an analysis of the major types of moves and countermoves individuals or groups adopt when they bring their conflict to the bargaining table and engage in explicit bargaining.

Concession behavior in explicit bargaining has symbolic import and is likely to be read very carefully by parties in conflict, especially since norms of explicit bargaining generally prevent the retraction of concessions, once given. Furthermore, it is well documented that concession tactics that appear too reasonable (i.e., create an impression of weakness) raise the aspirations and reduce the yielding of an opponent, while patterns that appear too unreasonable often backfire and produce resistance (Komorita \& Esser 1975; Siegel \& Fouraker 1960; Pruitt 1981). Research indicates that concession tactics conveying a firm but reasonable impression are generally the most effective at extracting concessions from an opponent (Chertkoff \& Esser 1976; Lawler \& MacMurray 1980). A commonly effective way to create such an impression is a very firm initial stance in the bargaining, involving little or no yielding, followed by reciprocal concession making. However, if both parties adopt this approach, the result is a pattern of mutual resistance or an impasse from which actors may not be able to extricate themselves without the aid of third parties. 
The theory of unilateral initiatives offers to bargainers a straightforward response to this problem. Given a pattern of mutual resistance or hostility, unilateral initiatives represent a break with the immediate past that ostensibly mitigates the problem of distrust created by early interchanges (Lindskold 1978; Osgood 1962). Unilateral initiatives represent a bridge between mutually firm posturing in the early phase of bargaining and subsequent, mutual reciprocity. Retaliation tactics, in turn, help to inhibit a key form of tactical action (damage) that tends to interfere with conflict-resolution processes. Our theoretical formulation treats unilateral initiatives and retaliation tactics as primary means of producing conciliation following a period of mutual antagonism in explicit bargaining.

The results of the study offer substantial support to the theory. As expected, unilateral initiatives produced larger concessions and fewer damage tactics than a reciprocity tactic. Moreover, unilateral initiatives generated the increase in trust predicted by the literature on Osgood's (1962) notion of GRIT; in addition, trust mediated the impact of unilateral initiatives on both concession making and damage tactics. Thus, as predicted, unilateral initiatives increased trust, which, in turn, enhanced concession making and reduced punitive action by fhe opponent.

In the case of retaliation, the results offer partial support to our theoretical formulation, but with a few interesting twists. First, retaliation does not have the predicted effect on concession making of the opponent, indicating the elimination of the causal path from retaliation to concession magnitude in Figure 1. Second, the contrasting patterns of punitive action over time in the retaliation condition (i.e., a decrease) versus the no-retaliation condition (i.e., an increase) supports and complements our theoretical formulation. In the short term, retaliation behavior actually enhanced hostility (see also Gruder \& Duslak 1973; Lawler, Ford \& Blegen 
1988), but, in the longer term, the costs of retaliation probably override this initial tendency toward hostility, especially since each party has a large punitive capability. In the no-retaliation condition, the use of damage tactics is lower early but grows over time, despite there being no direct and immediate benefit from the damage inflicted on the opponent. The most plausible interpretation of this result is that repeated instances of no retaliation conveyed an impression of weakness, leading the subject to view the opponent as more vulnerable to influence through punitive action.

The final result of import concerns the combination of tactics optimal for producing agreements. Unilateral initiatives in conjunction with retaliation was the only combination that produced an agreement rate of over 50\%. While agreements in experiments with programmed others must be interpreted cautiously, this result can be interpreted in terms of the impressions likely to be given off by the four tactics created by the experimental conditions. The combination of reciprocity (no initiative) and retaliation may make the programmed other appear too unreasonable in light of the initial period of hostility; the initiatives-and-no-retaliation combination may create an impression that is too conciliatory; and the combination of reciprocal concessions (no initiatives) and no retaliation may be puzzling or confusing. Combining unilateral initiatives with a retaliation tactic seems most likely to convey a serious interest in conflict resolution, in conjunction with an unwillingness to tolerate punitive action or to accept exploitation by the other, i.e., a firm but reasonable stance.

This study has several general implications. First, while Lindskold and associates (1976) have shown how verbal expressions of intent and patterns of cooperative behavior affect conciliation in tacit forms of bargaining instantiated by a prisoner's dilemma setting (Linkskold 1979; Lindskold, Bennett \& Wayner 1976; Lindskold \& Collins 1978; Lindskold \& Finch 1981), 
we have demonstrated the impact of a program of unilateral concessions in explicit bargaining (see also Hamner 1974). This program of initiatives involved somewhat greater risk of exploitation than some of Lindskold's (1978) practical guidelines would suggest, because it incorporated real concessions that cumulated over a series of bargaining interchanges (rounds). Second, while the success of a reciprocity strategy is well documented in research on the prisoner's dilemma (see Axelrod 1984; Patchen 1988), the theory of unilateral initiatives indicates a way to promote cooperation when a pattern of resistance and hostility is already established. Third, this study suggests that when a lock-in of mutual hostility occurs in explicit bargaining, some degree of trust — defined as an attribution- based expectation of cooperation — is important to generate the transformation from mutual conflict to mutual conciliation.

To conclude, our theoretical and empirical work leads us to several hypotheses about the conditions important for unilateral initiatives to effectively produce conflict resolution. First, parties in conflict have established an explicit bargaining relationship; second, parties perceive each other as having approximately equal power; third, the unilateral initiatives represent a significant departure from a background of hostility that occurs after the onset of explicit bargaining; fourth, the unilateral initiatives involve small, repetitive actions that cumulate to real movement along a conflict issue; and, fifth, through other, independent action (e.g., retaliation) the party that adopts the unilateral initiatives creates an image of firmness and resolve. While additional conditions are likely to be important, these are basic ones that have emerged from the theoretical and empirical analysis. Given the potential importance of unilateral initiatives to conflict resolution, such tactics warrant more sustained focus and attention by sociologists. 


\section{Notes}

1. More specifically, explicit bargaining occurs where parties (1) mutually acknowledge a bargaining relationship, (2) perceive the conflicting issue(s) as allowing for a large range of possible solutions, and (3) have open lines of communication in which they make offers and counteroffers along an issue continuum (Bacharach \& Lawler 1980:108-20). Conflict resolution, in this context, involves an explicit, often formal mutual agreement. Another form of bargaining, often termed "tacit" (Bacharach \& Lawler 1980; Schelling 1960), is reflected in the efforts of parties to outmaneuver each other in most any conflict. In tacit baigaining, parties acknowledge a conflict without consenting to figuratively "sit at the bargaining table." Conflict resolution in such contexts takes the form of implicit coordination.

2. When a matrix game is used as an actual laboratory research setting, the bargaining is tacit rather than explicit. There is no clear bargaining issue with a range of possible solutions, and provisional offers and counteroffers are not really possible. Only action with rewarding (cooperative) or punishing (competitive) consequences is available. Overall, iterative matrix games induce a social context similar to that which occurs when parties are in conflict but are not bargaining explicitly. The action of labor and management outside of contract negotiations and of nations in international conflict exemplifies such tacit bargaining.

3. The meaning of the competitive choice in the prisoner's dilemma is not clear (see Marwell \& Schmitt 1975; Nemeth 1972). It is both a noncooperative action (i.e., failure to make a conciliatory move) and a punishing action (i.e., damage to the other's outcomes). The cooperative-competitive label intertwines the positive and negative dimensions of behavior that are separable in explicit bargaining. Concession behavior consists of the provisional offers or 
counteroffers along the issue continuum, and punitive behavior refers to action that damages resources or outcomes of the opponent that are not under direct negotiation. A decision on one class of action does not by definition involve a decision on the other.

4. Conceptually, we argue that trust has two components: (1) a dispositional attribution, meaning an inference about the other person, e.g., trustworthiness, reasonableness; and (2) an application of this attribution to the others behavior in the situation, e.g., an expectation of cooperation. Thus, trust is essentially an expectation of cooperation based on an attribution of qualities to the other person. This is a modification of definitions incorporating only the behavioral expectations component (e.g., Pruitt 1981).

5. Research with these experimental procedures across a number of years has typically yielded no or very weak results for gender (Bacharach \& Lawler 1981; Lawler \& Bacharach 1987; Lawler, Ford \& Blegen 1988; Lawler \& MacMurray 1980). Either gender seemingly can be used at this point. The use of males in this study was based solely on the nature of the subject pool available.

6. The results for threat tactics (warning) are generally consistent with those for damage tactics. An analysis of variance for the early phase (rounds 6-10) revealed an initiatives main effect that mirrors the findings for damage tactics $\left[F(1,76)=11.36, p<.001, M^{\prime} s=.90\right.$ vs. 1.75]. Neither retaliation nor initiatives-by-retaliation effects reached statistical significance. Turning to the use of threat tactics in the subsequent or later phase, the results revealed only a retaliation main effect, indicating fewer warnings in the retaliation condition $[F(1,76)=4.13$, $p<.05]$. While previous work has frequently documented minimal correspondence between results for threat and damage tactics (Bacharach \& Lawler 1981; Lawler \& Bacharach 1987; Lawler, Ford \& Blegen 1988), this study has fairly comparable effects. 
7. Given fairly clear theoretical expectations about how the items will cluster, setting a limit of two factors seems justified (see Kim \& Mueller 1978). Since this procedure is open to question, however, we also conducted a factor analysis (varimax rotation) without any limit. The results are the same. Trust and predictability factors emerged with eigenvalues of 1.597 and 1.769, respectively. The third factor had an eigenvalue of .85 and lacked a clear theoretical interpretation. 


\section{Figure 1}

\section{FIGURE 1: Diagram of Theory}

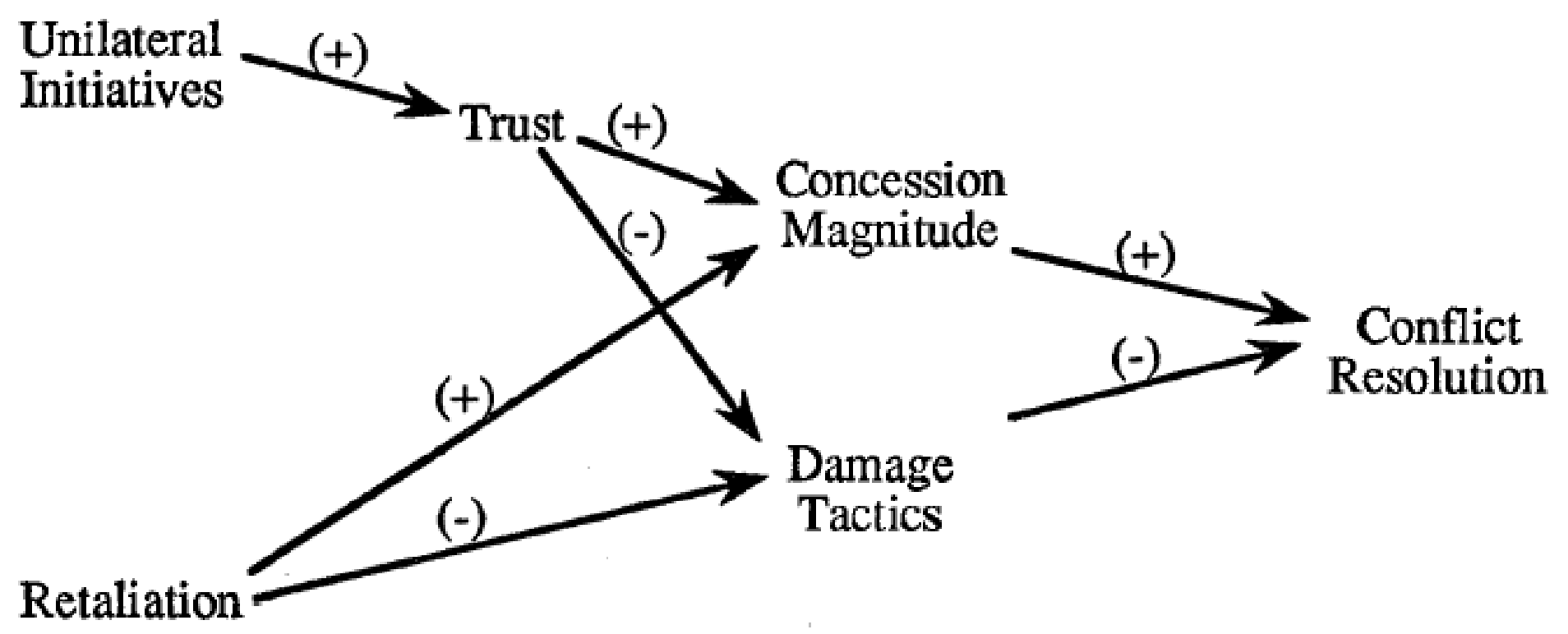


Figure 2

FIGURE 2: Concession Magnitude by Round Block

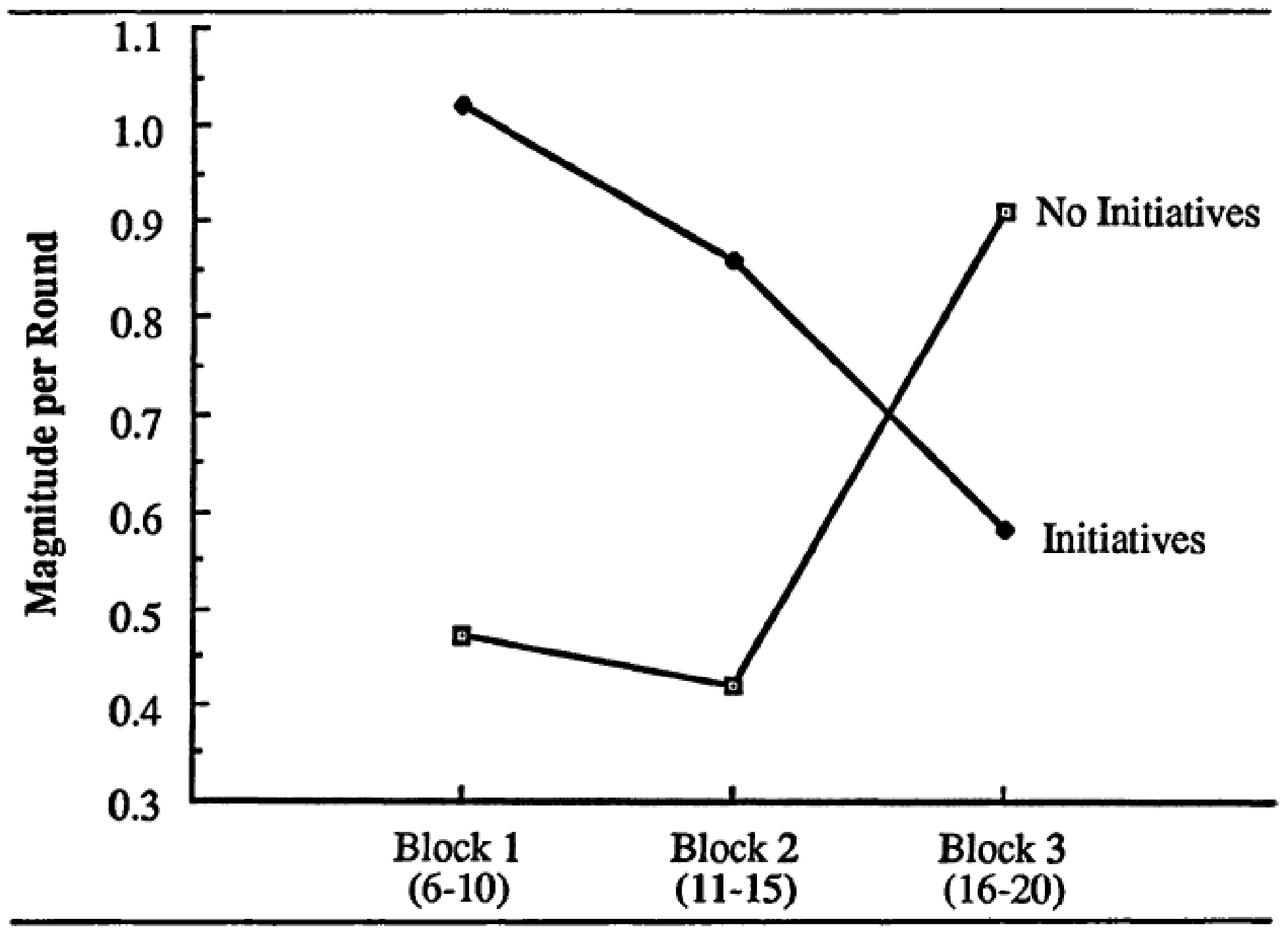


Figure 3

\section{FIGURE 3: Damage Tactics by Round Block}

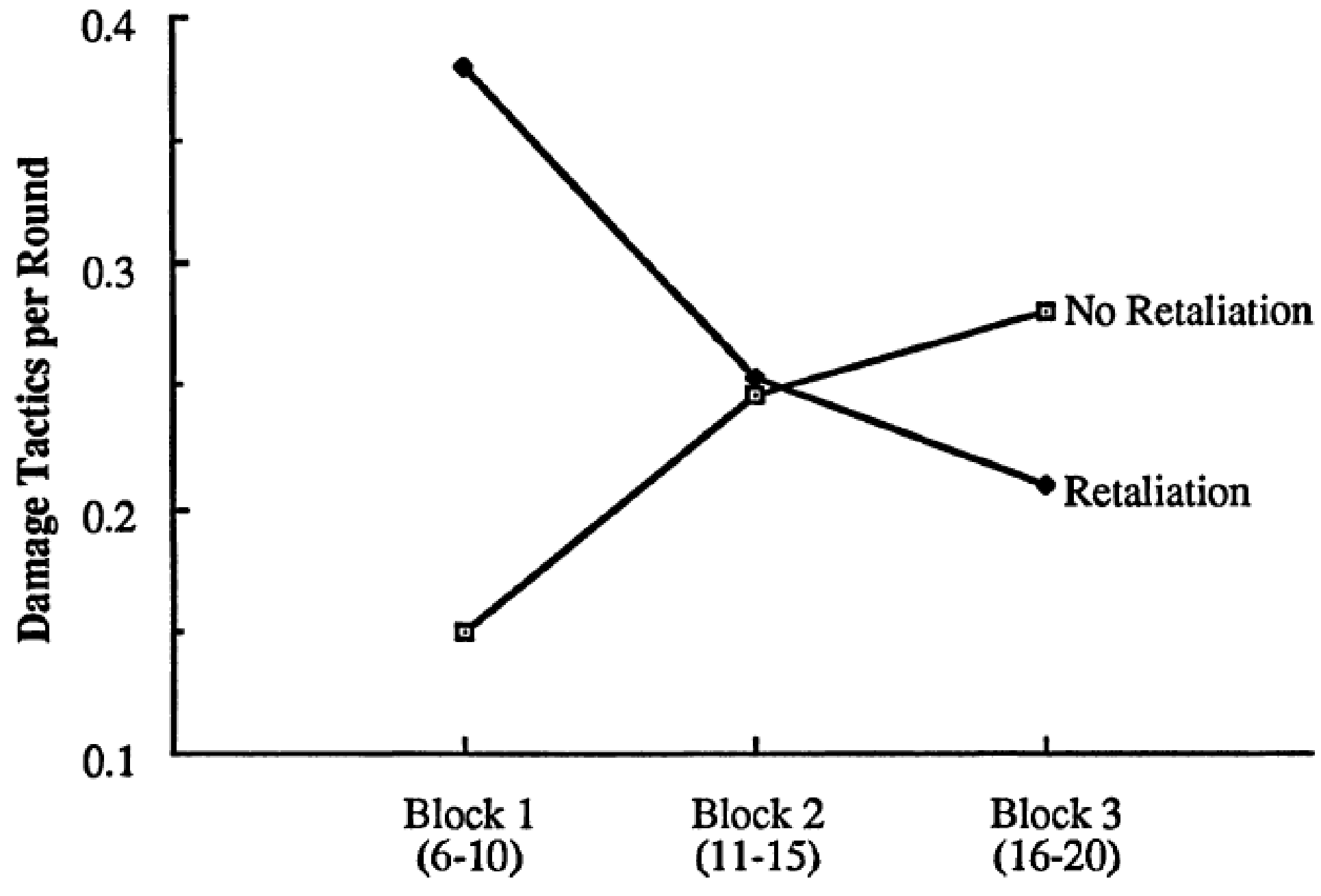


TABLE 1: Mean Fine Use, Concession Magnitude, and Agreement by Experimental Conditions

\begin{tabular}{cccc}
\multicolumn{2}{c}{ Initiatives } & \multicolumn{2}{c}{ No Initiatives } \\
Retaliation & No Retaliation & Retaliation & No Retaliation \\
6.75 & 5.00 & 2.55 & 2.30 \\
7.60 & 6.60 & 6.50 & 7.10 \\
1.20 & .40 & 2.50 & 1.00 \\
1.05 & 1.95 & 2.95 & 3.10 \\
& .35 & .15 & .25
\end{tabular}

Early concessions

Later concessions

Early fines

Later fines

Proportion of agreement
6.75

7.60

1.20

.75
Table 1

Initiatives 
Table 2

TABLE 2: Postexperiment Questionnaire Measure by Experimental Condition

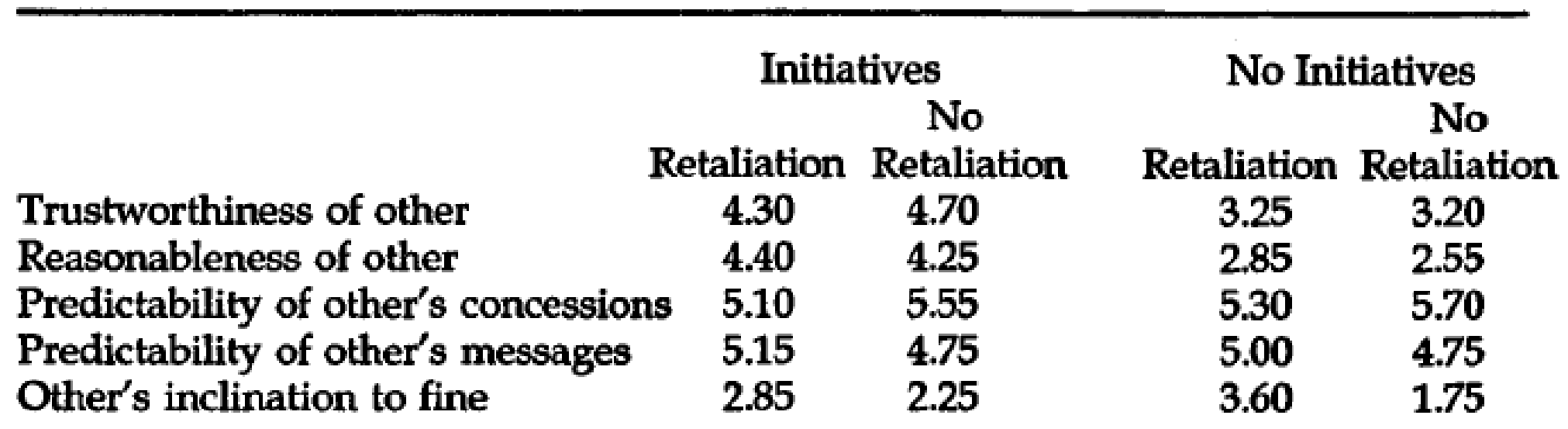

Trustworthy

Predictability of messages

Predictability of concessions

Reasonable

Other's fines

Total variance
.030

.903

.843

.078

.486

35.37
Factor Structure

Correlation Matrix

.868

.113

.040

.792

$-.450$

31.95
Trustworthy

Predictability of messages

Predictability of concessions

Reasonable

Other's fines
Trust. Predict. Predict. Reason. Other's

1.000 Messages Concess.

Fines

$.092 \quad 1.000$

$\begin{array}{lll}.045 & .124 & 1.000\end{array}$

$\begin{array}{llll}.485 & .124 & -.024 & 1.000\end{array}$

$\begin{array}{lllll}-.271 & .293 & .144 & -.088 & 1.000\end{array}$ 
Table 3

TABLE 3: Standardized Regression Coefficients from Regression of Manipulated Variables, Trust, and Controls on Concession Magnitude (Later) and Frequency of Damage (Later)

\begin{tabular}{lcccccc}
\hline & \multicolumn{3}{c}{ Damage Tactics } & \multicolumn{3}{c}{ Concessions } \\
& 1 & 2 & 3 & 4 & 5 & 6 \\
Initiatives & $-.288^{\star}$ & -.108 & -.018 & -.043 & -.272 & -.290 \\
Retaliation & -.038 & -.032 & -.015 & -.051 & -.077 & -.018 \\
Initiatives x retaliation & -.163 & -.106 & -.185 & .119 & .156 & .073 \\
Trust & & $-.471^{\star \star}$ & $-.440^{\star \star}$ & & $.406^{\star \star}$ & $.386^{\star \star}$ \\
Controls & & & $(a)$ & & & $(a)$ \\
$\mathrm{R}^{2}$ & .172 & .334 & .380 & .006 & .126 & .158 \\
\hline
\end{tabular}

(a) Controls for concession magnitude and frequency of damage in previous periods of the bargaining

${ }^{*} \mathrm{p}<.05 \quad$ * $\mathrm{p}<.01 \quad$ ** $\mathrm{p}<.001$

Correlation Matrix

Initiatives Retaliation Trust Damage Concessions

Initiatives

Retaliation

Trust

Damage

Concessions
1.000

$.000 \quad 1.000$

$.513 \quad .009$

$-.382$

.026
$-.131$

.017
1.000

$\begin{array}{rl}-.538 & 1.000\end{array}$

$.307 \quad-.235$ 


\section{References}

Axelrod, Robert. 1984. The Evolution of Cooperation. Basic Books.

Bacharach, Samuel B., and Edward J. Lawler. 1980. Power and Politics in Organizations. Jossey- Bass.

1981. Bargaining: Power, Tactics, and Outcomes. Jossey-Bass.

Benton, Alan A., Harold H. Kelley, and Barry Liebling. 1972. "Effects of Extremity of Offers and Concession Rate on the Outcomes of Bargaining." Journal of Personality and Social Psychology 24:73-83.

Blalock, Hubert M., Jr. 1987. "A Power Analysis of Conflict Processes." Pp.1-40 in Advances in Group Processes. Vol. 4, edited by Edward J. Lawler and Bany Markovsky. JAI Press.

_. 1989. Power and Conflict: Toward a General Theory. Sage.

Chertkoff, Jerome M., and James K. Esser. 1976. "A Review of Experiments in Explicit Bargaining." Journal of Experimental Social Psychology 12:464-86.

Dahrendorf, Ralf. 1959. Gass and Gass Conflict in Industrial Society. Stanford University Press.

Deutsch, Morton. 1973. The Resolution of Conflict: Constructive and Destructive Processes. Yale University Press.

Deutsch, Morton, Yakov Epstein, Donnah Canavan, and Peter Gumpert. 1967. "Strategies for Inducing Cooperation." Journal of Conflict Resolution 11:345-60.

Etzioni, Amitai. 1967. "The Kennedy Experiment." Western Politico! Science Quarterly 20:31680.

Gouldner, Alvin. 1960. "The Norm of Reciprocity: A Preliminary Statement." American Sociological Review 25:161-78. 
Gruder, Charles L., and Robert J. Duslak. 1973. "Elicitation of Cooperation by Retaliatory and Nonretaliatory in a Mixed-Motive Game." Journal of Conflict Resolution 17:162-74. Hamner, W. Clay. 1974. "Effects of Bargaining Strategy and Pressure to Reach Agreement in Stalemated Negotiations." Journal of Personality and Social Psychology 30:458-67.

Kim, Jae-On, and Charles W. Mueller. 1978. Factor Analysis: Statistical Methods and Practical Issues. Sage.

Komorita, Samuel S., and Arline R. Brenner. 1968. "Bargaining and Concession Making under Bilateral Monopoly." Journal of Personality and Social Psychology 9:15-19.

Komorita, Samuel S., and James K. Esser. 1975. "Frequency of Reciprocated Concessions in Bargaining." Journal of Personality and Social Psychology 32:699-705.

Kriesberg, Louis. 1973. The Sociology of Social Conflicts. Prentice-Hall.

Lawler, Edward J. N.d. "Power Processes in Bargaining." Sociological Quarterly. Forthcoming. Lawler, Edward J., and Samuel B. Bacharach. 1987. "Comparison of Dependence and Punitive Forms of Power." Social Forces 66:446-62.

Lawler, Edward J., Rebecca S. Ford, and Mary A. Blegen. 1988. "Coercive Capability in Conflict: A Test of Bilateral Deterrence vs. Conflict Spiral Theory." Social Psychology Quarterly 51:93-107.

Lawler, Edward J., and Bruce K. MacMurray. 1980. "Bargaining Toughness: A Qualification of Level-of-Aspiration and Reciprocity Hypotheses." Journal of Applied Social Psychology $10: 416-30$.

Lindskold, Svenn. 1978. "Trust Development, the GRIT Proposal, and the Effects of Conciliatory Acts on Conflict and Cooperation." Psychological Bulletin 85:772-93. 
1979. "Conciliation with Simultaneous or Sequential Interaction." Journal of Conflict Resolution 23:704-14.

Lindskold, Svenn, and Jonathan Aronoff. 1980. "Conciliatory Strategies and Relative Power." Journal of Experimental Social Psychology 16:187-98.

Lindskold, Svenn, Russell Bennett, and Marc Wayner. 1976. "Retaliation Level As a Foundation for Subsequent Conciliation." Behavioral Science 21:13-18.

Lindskold, Svenn, and Michael G. Collins. 1978. "Inducing Cooperation by Groups and Individuals." Journal of Conflict Resolution 22:679-90.

Lindskold, Svenn, and Marta L. Finch. 1981. "Styles of Announcing Conciliation." Journal of Conflict Resolution 25:145-55.

Marwell, Gerald, and David R. Schmitt. 1975. Cooperation: An Experimental Analysis. Academic Press.

Nemeth, Charlan. 1972. "A Critical Analysis of Research Utilizing the Prisoner's Dilemma Paradigm for the Study of Bargaining." Pp. 203-34 in Advances in Experimental Social Psychology. Vol. 6, edited by Leonard Berkowitz. Academic Press.

Osgood, Charles. 1962. An Alternative to War or Surrender. University of Illinois Press.

Oskamp, Stuart. 1971. "Effects of Programmed Strategies on Cooperation in the Prisoner's Dilemma and Other Mixed-Motive Games." Journal of Conflict Resolution 15:225-59.

Patchen, Martin. 1987. "Strategies for Eliciting Cooperation from an Adversary." Journal of Conflict Resolution 31:164-85. . 1988. Resolving Disputes between Nations. Duke University Press.

Pilisuk, Marc. 1984. "Experimenting with the Arms Race." Journal of Conflict Resolution 28:296- 315. 
Pruitt, Dean G. 1981. Negotiation Behavior. Academic Press.

Rubin, Jeffrey Z., and Bert R. Brown. 1975. The Social Psychology of Bargaining and Negotiation. Academic Press.

Schelling, Thomas C. 1960. The Strategy of Conflict. Oxford University Press.

Siegel, Sidney, and Lawrence E. Fouraker. 1960. Bargaining and Group Decision Making. McGraw- Hill.

Simmel, Georg. 1950. The Sociology of Georg Simmel. Translated by Kurt Wolff. Free Press.

Strauss, Anselm. 1978. Negotiations. Jossey-Bass.

Wrightsman, Lawrence S., John O'Conner, and Norma J. Baker (eds.). 1972. Cooperation and Competition. Brooks-Cole.

Youngs, George A., Jr. 1986. "Patterns of Threat and Punishment Reciprocity in a Conflict Setting." Journal of Personality and Social Psychology 51:541-46.

Yukl, Gary A. 1974. "Effects of the Opponent's Initial Offer, Concession Magnitude, and Concession Frequency on Bargaining Behavior." Journal of Personality and Social Psychology 30:323-35. 